\section{Representações sociais de profissionais de saúde sobre violência sexual contra a mulher: estudo em três maternidades públicas municipais do Rio de Janeiro, Brasil}

\author{
Social representations by health professionals \\ of sexual violence against women: \\ a study in three municipal public maternity \\ hospitals in Rio de Janeiro, Brazil
}

Ludmila Fontenele Cavalcanti 1,2

Romeu Gomes 3

Maria Cecília de Souza Minayo 3,4

\footnotetext{
${ }^{1}$ Escola de Serviço Social, Universidade Federal do Rio de Janeiro, Rio de Janeiro, Brasil. 2 Conselho Estadual de Direitos da Mulher, Rio de Janeiro, Brasil. 3 Instituto Fernandes Figueira, Fundação Oswaldo Cruz, Rio de Janeiro, Brasil. 4 Escola Nacional de Saúde Pública Sergio Arouca, Fundação Oswaldo Cruz, Rio de Janeiro, Brasil.

Correspondência L. F. Cavalcanti Escola de Serviço Social, Universidade Federal do Rio de Janeiro. Rua Gustavo Sampaio 208, apto. 1201, Rio de Janeiro, $R$ 22010-010, Brasil.

ludmario@terra.com.br
}

\begin{abstract}
The purpose of this study was to analyze social representations of sexual violence against women, as constructed and reproduced in prenatal care settings in three municipal maternity hospitals in Rio de Janeiro, Brazil. This qualitative research explored two themes: ideas about and explanations of sexual violence committed against woman. The forty-five interviews conducted with health professionals were examined using thematic content analysis. The results show that social representations of sexual violence against women were associated with ideas of suffering, behavioral disturbances, and forced sexual intercourse. The explanations offered for why this type of violence occurs included gender relations, urban violence, and ascription of blame to the victim. It can be concluded that hegemonic patterns of asymmetrical relations persist, even in the discourse of maternity health professionals, who are the point of reference for attending to victims of sexual violence. Incorporating the analytical category of gender into healthcare professional training could make prenatal care an important gateway for the recognition and management of sexual violence against women.
\end{abstract}

Violence; Women's Health; Prenatal Care

\section{Introdução}

O presente artigo tem por objetivo analisar as representações sociais da violência sexual contra a mulher, construídas e reproduzidas no contexto da assistência pré-natal em três maternidades públicas municipais do Rio de Janeiro, Brasil. Esse objetivo é parte de uma pesquisa realizada para a elaboração de uma tese de doutorado 1 .

A violência sexual contra a mulher é entendida neste trabalho como a ação ou conduta em que ocorre o controle e a subordinação da sexualidade da mulher e é incorporada como constitutiva das regras que normatizam a prática sexual 1 . No conjunto das violências cometidas contra a mulher, esse tipo de violência assume um significado especial, pois quase sempre vem acompanhada de outras expressões 2,3,4

Diferentes pesquisas internacionais e nacionais estimam que uma entre quatro mulheres vivencie alguma forma de violência sexual perpetrada por parceiro íntimo, e quase um terço das adolescentes teve sua primeira experiência sexual forçada 5 . Vários estudos vêm apontando o comprometimento da saúde da mulher por conta desse tipo de violência 6,7 .

A assistência pré-natal pode favorecer a detecção de problemas relacionados a esse tipo de violência, uma vez que, ao se abordar a gravidez, a discussão sobre o corpo feminino pode ser desenvolvida ${ }^{8}$. Por intermédio dessa dis- 
cussão, numa perspectiva relacional de gênero, as ações da assistência pré-natal podem incluir a temática da violência sexual, assumindo um espaço privilegiado de prevenção e de assistência a esse agravo.

Todavia, para que se possa caminhar nessa direção, um dos aspectos importantes é compreender como a violência sexual contra a mulher é representada pelos profissionais de saúde da assistência pré-natal.

As representações sociais são aqui entendidas como sistemas de interpretação que regem a relação dos sujeitos com o mundo e com os outros 9,10 , podendo ser produtos tanto de idéias socialmente reproduzidas quanto de modificações ocorridas por intervenções históricas e sociais. Nesse sentido, a representação não é um simples reflexo do real, mas sua construção, que ultrapassa o próprio indivíduo, revelando a existência de fenômenos coletivos 11 .

Em sua essência, uma representação social é um saber prático que orienta a ação e se expressa de forma simbólica em geral (como é o caso da visão cultural do papel subordinado da mulher) ou dentro de grupos específicos (como é o caso da visão da sexualidade por homens, mulheres e profissionais de saúde).

Não se pode também desconsiderar, todavia, como observam Gomes \& Mendonça 12, a inter-relação entre os pólos subjetivo e contextual das representações sociais. Tal inter-relação se configura pela reconstrução da intersubjetividade concomitantemente com a produção e a reprodução de idéias socialmente constituídas, por meio de negociações dos atores.

Compreender a representação dos profissionais de saúde sobre violência sexual pode facilitar a promoção de estratégias de prevenção para esse agravo. Assim, as maneiras como os profissionais de saúde da assistência representam a violência sexual tanto refletem a sua própria formação e vivência como pessoa quanto integram as práticas no contexto da unidade de saúde.

\section{Percurso metodológico}

O estudo vale-se do pressuposto de que as representações dos profissionais de saúde da assistência pré-natal das maternidades que são referência para o atendimento às mulheres vítimas de violência sexual estão condicionadas pelo processo de capacitação e pela experiência no atendimento, sendo capazes de conferir uma maior visibilidade ao problema e permitir a implantação de estratégias mais amplas de prevenção da violência sexual.
A compreensão e a análise das representações sociais dos profissionais de saúde da assistência pré-natal sobre a violência sexual tiveram como referência a abordagem qualitativa, que se volta para os significados e a intencionalidade das ações nos contextos das estruturas sociais 9 .

Nesse sentido, a pesquisa buscou trabalhar com dois núcleos temáticos: as idéias associadas à violência sexual cometida contra a mulher (seja perpetrada no espaço público ou privado) pelos profissionais de saúde e as explicações para a ocorrência dessa violência, entendida como as causas atribuídas ao controle e subordinação da sexualidade feminina.

O trabalho de campo foi desenvolvido em três maternidades da Secretara Municipal de Saúde do Rio de Janeiro (SMS/RJ), sendo duas as únicas de referência para o atendimento às mulheres vítimas de violência sexual, no momento da pesquisa. A terceira não possui essa atribuição e foi integrada ao campo de estudo para servir de base comparativa, visto que possui perfil semelhante ao das primeiras. Entre as unidades de referência, foram estudados o Hospital Maternidade Alexander Fleming (HMAF) e o Instituto Municipal da Mulher Fernando Magalhães (IMMFM). A terceira foi o Hospital Maternidade Carmela Dutra (HMCD).

O grupo social alvo desta investigação são os profissionais de saúde envolvidos no cuidado direto à gestante na assistência pré-natal (médicos, psicólogos, enfermeiros, assistentes sociais, odontólogos e nutricionistas), lotados em três maternidades da SMS/RJ e divididos em dois subgrupos (das unidades-referência e da unidade não considerada de referência). $\mathrm{Na}$ busca de aprofundamento e abrangência da compreensão deste grupo social, bem como diversidade na sua formação, os profissionais foram incluídos com base nos seguintes critérios: (a) pertencimento ao quadro funcional da maternidade; (b) envolvimento no cuidado direto à gestante; (c) atuação na assistência prénatal por um período acima de um ano. Foram considerados apenas os profissionais de nível superior em razão de sua centralidade no contexto das maternidades.

Inicialmente foi realizado levantamento do perfil das instituições e dos profissionais de saúde da assistência pré-natal, seguido do trabalho empírico que constou de entrevistas com 45 profissionais, sendo 19 do HMAF, 11 do IMMFM e 15 do HMCD. Os entrevistados variaram em quantidade e qualidade, conforme a organização da assistência pré-natal de cada maternidade e a inserção dos mesmos nas categorias profissionais abordadas. 
Com o objetivo de garantir o anonimato dos pesquisados, nos fragmentos das entrevistas, serão utilizados os seguintes códigos: Mo (médico), Ma (médica), P (psicóloga), Eo (enfermeiro), Ea (enfermeira), AS (assistente social), Oo (odontólogo), Oa (odontóloga) e N (nutricionista). Após esse código segue um número correspondente à seqüência das entrevistas.

No tratamento dos dados, foi utilizada a análise de conteúdo temática 9,13. "Fazer uma análise temática, consiste em descobrir os 'núcleos de sentido' que compõem a comunicação e cuja presença, ou freqüência de aparição pode significar alguma coisa para o objetivo analítico escolhido" 13 (p. 105). Nesse procedimento analítico, "núcleo de sentido" é visto como uma unidade de significação no conjunto de uma comunicação ${ }^{13}$. Neste estudo, os núcleos de sentidos foram entendidos como idéias-eixo em torno das quais giram outras idéias. Mediante a análise temática, também se pode caminhar na direção da "descoberta do que está por trás dos conteúdos manifestos, indo além das aparências do que está sendo comunicado" 14 (p. 74).

A análise percorreu os seguintes passos: (a) leitura inicial procurando ter uma compreensão global do material; (b) identificação das unidades de significado que emergiram das falas dos entrevistados por unidade de saúde; (c) comparação das diferentes unidades de significado nos dois grupos de maternidades; (d) descoberta de núcleos de sentido em torno dos quais giraram a construção das representações e (e) interpretação e discussão dos núcleos de sentido encontrados.

A pesquisa original foi aprovada pelo Comitê de Ética do Instituto Fernandes Figueira, Fundação Oswaldo Cruz. Esse procedimento seguiu recomendações da Resolução 196/1996 do Conselho Nacional de Saúde, que regulamenta investigações envolvendo seres humanos.

\section{As idéias associadas à violência sexual cometida contra a mulher}

No conjunto das falas dos profissionais entrevistados, a violência sexual cometida contra a mulher se encontra representada por idéias associadas, que foram classificadas em três núcleos de sentido: (1) sofrimento, (2) distúrbio do comportamento e (3) relação sexual forçada.

O núcleo de sentido de sofrimento se associou: à "marca 'que fica pra sempre”" (Ea5) na mulher; à "agressão física [que] dó $i$ " (...), à "agressão não-física [que] também dói" (Ma8) e a "um problema muito sério para a mulher porque elas ficam traumatizadas” (P2).
O sofrimento, como uma idéia associada à violência sexual, é mais freqüente entre os(as) enfermeiros(as) e as médicas. Esse sofrimento a que se referem os profissionais entrevistados, por envolver dor e trauma, é visto por meio de um olhar biomédico que reconhece a violência sexual como uma experiência corporal feminina, podendo ser compreendida por intermédio de signos e sintomas passíveis de diagnóstico e tratamento. Tal ênfase se relaciona ao fato de a área da saúde, tradicionalmente, concentrar esforços em atender aos agravos que a violência sexual provoca.

Por outro lado, essa forma de conceber os efeitos dessa violência também faz parte de um contexto social mais amplo, pois as seqüelas físicas e psicológicas por ela produzidas têm se tornado mais visíveis com a socialização da discussão do fenômeno. Sabe-se hoje que as mulheres atingidas ficam mais vulneráveis a outros tipos de violência, à prostituição, ao uso de drogas, à gravidez indesejada, às doenças ginecológicas, aos distúrbios sexuais, à depressão, ao suicídio e às infecções sexualmente transmissíveis.

Embora no âmbito dos serviços de saúde, o reconhecimento dos danos causados pela violência sexual seja fundamental à orientação das condutas, o modelo explicativo medicalizante acaba por obscurecer a abrangência e a polissemia do termo sofrimento em relação ao problema aqui tratado. É importante ressaltar que a violência sexual assume um papel diferenciado no conjunto das violências de gênero, sobretudo pelo seu maior encobrimento comparado às formas de agir em relação às demais modalidades e pelo sofrimento causado no terreno da sexualidade. "As mulheres que passam por abuso físico e sexual perpetrado por parceiros íntimos estão, de forma geral, sob maior risco de problemas de saúde do que as que passam somente pela violência física" 5 (p. 161).

A magnitude desse sofrimento é estimada pelo Banco Mundial ao afirmar "que o estupro $e$ a violência doméstica causam uma perda anual de 9 milhões de anos de vida produtiva (AVAI) no mundo" 15 (p. 30). As conseqüências, no caso da violência sexual, podem durar vários anos. Estudos realizados nos Estados Unidos mostram que $25 \%$ das vítimas de estupro continuam exibindo sintomas disfuncionais durante quatro a seis anos após o evento 16 .

Assim como ocorre uma variação cultural na linguagem sobre sofrimento, como afirma Helman 17, que acaba se tornando localizada, cada sistema de saúde também legitima, particularmente com base na enfermidade, a atenção a determinados segmentos, nesse caso, as 
vítimas de violência sexual. Na perspectiva do modelo médico-científico moderno, a enfermidade é situada fora do corpo do indivíduo, enfatizando os processos fisiológicos e patológicos para explicar como e por que determinadas pessoas adoecem.

A denominação às vítimas de violência sexual como "VVS" pelos profissionais entrevistados, como vem ocorrendo nas unidades, ainda que aponte para uma incorporação desse agravo no atendimento, pode operar sua redução a uma mera entidade passível de receber tratamento tópico e ocasional, limitando a complexidade das razões subjetivas a que têm direito as usuárias. Nesse sentido, "a violência experimentada pelas mulheres e seus efeitos na vida e na saúde não encontram canais de expressão ou comunicação, já que possuem códigos, nomeações ou linguagens que lhe seriam próprias" 18 (p. 22).

Concorda-se com Rozemberg \& Minayo 19, ao discutirem os reducionismos na abordagem da saúde/doença, que os saberes biomédico e psicológico, de bases positivistas, não esgotam as questões constitutivas do adoecimento dos sujeitos. A área da saúde, historicamente marcada pela hegemonia desse tipo de lógica, tem dificuldades de acolher as razões culturais.

Schraiber \& D'Oliveira 18 chamam a atenção para o risco de se aplicar o conceito de doença à violência. Tal postura promoveria o acirramento da idéia de vitimização e reforçaria os estereótipos correntes de que as mulheres agredidas seriam sujeitos incompletos e carentes de tutela especializada.

Um segundo núcleo de sentido se refere ao distúrbio do comportamento. Muitos profissionais entrevistados concebem a sexualidade masculina como um imperativo biológico, o mesmo estereótipo que domina a visão do senso comum. E também acrescentam circunstâncias em que esse imperativo se torna peremptório para os homens, cuja insatisfação acarretaria conseqüências nefastas como irritação e nervosismo.

Desse modo, o agressor é visto como portador de "algum distúrbio de comportamento, até mesmo de infância, de vida sexual [e que] pode estar ou drogado ou alcoolizado" (Oa2) ou como "aquele doente (...) que quer ter relações todos os dias e acha que a mulher é obrigada (...) $e$ parte para a violência sexual" (Ma15).

Tais idéias, predominantes nos discursos femininos, especialmente nos das profissionais de enfermagem e de odontologia, reafirmam a representação da sexualidade masculina como único lugar de iniciativa e a naturalização da apropriação sexual e social do corpo feminino.
A representação que reforça a assimetria na esfera da sexualidade promove a inibição do desejo feminino. Além disso, a visão da sexualidade masculina como necessidade e impulso biológico instintivo, aplicada à sexualidade feminina, legitima a dominação, o controle e a violência sexual cometida nas relações conjugais.

Os profissionais de saúde, ao explicitarem sua visão da violência sexual como distúrbios de comportamento, mostram que compartilham a idéia que relaciona virilidade e agressividade na relação entre homem e mulher. Especificamente, nos depoimentos dos profissionais do sexo masculino, os agressores são identificados como homens de "um temperamento agressivo com a companheira" (Ool) e aqueles “homens que são pervertidos sexuais" (Mo3). Há, portanto, nessa representação, uma forte associação entre ser violento e ser homem, reforçando marcas identitárias comumente relacionadas à masculinidade.

Ampliando a discussão acerca da associação entre masculinidade e violência, Machado 20 (p. 235) afirma: “o imaginário da 'sexualidade feminina como aquela que se esquiva para se oferecer' parece ser a contraparte do imaginário da sexualidade masculina como aquela que tem a iniciativa e que se apodera unilateralmente do corpo do outro".

Para esse autor, o ato da imposição sexual ganha a figura metafórica da imposição de poder, não somente sobre um corpo de mulher, mas sobre uma determinada mulher, pensada como pessoa. A violência sexual, nesse sentido, está associada à reafirmação da identidade masculina e à posse do corpo da mulher ao efeito simbólico de recolocá-lo no lugar hierarquicamente subordinado de esposa. O contexto familiar considerado como lugar de subordinação da esposa é marcado pelos valores patriarcais, tendo como características a reprodução, a monogamia, a durabilidade da união e a harmonia.

A persistência da idéia de que a sexualidade é moldada por forças internas, sobre as quais não existem controles por serem naturais, constitui-se num dos maiores obstáculos para erradicação das práticas sexuais violentas. Segundo Bourdieu 21, assim como o impulso sexual é construído em sociedade, as relações que vão mediar as práticas da sexualidade são criações culturais. Este autor, analisando o sentido social do ato sexual, comenta que aí também se dá uma relação de dominação, na medida em que as práticas e as representações dos dois sexos não são simétricas. A interação amorosa, na maior parte das vezes, é pensada 
pelos homens com a lógica da conquista. Nessas circunstâncias, o ato sexual, em si, é concebido como uma forma de apropriação e de posse.

Decorre desse fato o desencontro entre as expectativas dos homens e das mulheres em matéria de sexualidade, que, em seu sentido mais amplo, estão revestidas de significações distintas sobre sexualidade e poder.

A compreensão da violência sexual cometida contra a mulher, neste núcleo de sentido, também passa pelo entendimento de um padrão de normalidade no campo da sexualidade. Ancorada na tradição dualista sobre a construção social da identidade de gênero e da sexualidade, essa representação separa o corpo da mente e enfatiza os aspectos biológicos da sexualidade em detrimento de suas peculiaridades culturais.

O terceiro, e último núcleo de sentido, diz respeito à relação sexual forçada, em que a representação sobre o consentimento assume uma dimensão significativa nas falas dos profissionais de saúde entrevistados, por ser um dos elementos que estrutura a definição de violência sexual no campo dos direitos sexuais e reprodutivos. Assim, "violência sexual é relação sexual forçada, que a mulher não queria, que seja contra a vontade dela, qualquer ato sexual que não leve em conta a vontade da mulher" (AS6).

Tal representação coincide com a definição encontrada no Relatório Mundial sobre Violência e Saúde (World Report on Violence and Health - World Health Organization 5), em que a violência sexual compreende uma variedade de atos ou de tentativas de relação sexual sob coação ou fisicamente forçada no casamento ou em outros relacionamentos.

Coincide também com a visão da Rede Nacional Feminista de Saúde e Direitos Reprodutivos 22 (p. 125), que define violência sexual como: “(...) ação que obriga uma pessoa a manter contato sexual, físico ou verbal, ou a participar de outras relações sexuais com uso de força, intimidação, coerção, chantagem, suborno, manipulação, ameaça ou qualquer outro mecanismo que anule ou limite a vontade pessoal".

Conforme Zegarra Tarqui 23, a violência sexual consiste em toda ação que implica ameaça ou intimidação que afete a integridade ou a autodeterminação. Como por exemplo, a manipulação, o abuso sexual, o sexo forçado, as observações lascivas e o estupro.

O discurso sobre a violência sexual contra a mulher supõe uma relação de dominação e agressividade do parceiro, em parte influenciado pelo discurso jurídico, que, historicamente, perseguiu a materialidade para atestar o não consentimento da vítima 24 . A dominação presente na violência sexual cometida no casamento, mais do que em outras violências de gênero, dificulta sua compreensão pela maioria dos profissionais de saúde entrevistados, como um ato que contraria a vontade da vítima. Contudo, Schraiber \& D'Oliveira 18 afirmam a precedência da violência sexual em relação às demais concepções de violência contra a mulher, abrindo campo para evidenciar todas as demais. "A agressão sexual por um desconhecido é bastante diversa da mesma agressão cometida por uma pessoa próxima, íntima, que se ama (ou amou) e com quem se escolheu conviver, ainda que esta escolha seja algumas vezes mais próxima do constrangimento" 18 (p. 13-4).

As tendências à submissão, como coloca Bourdieu 25, dadas por vezes como pretexto para culpar a vítima, são resultantes de estruturas objetivas, que devem sua eficácia aos mecanismos que elas desencadeiam e que contribuem para sua reprodução. Com base nesse autor, pode-se considerar que o poder simbólico, presente na violência sexual contra a mulher, não pode ser exercido sem a colaboração da própria mulher. Tal poder, fortemente constituído por meio de discursos e comportamentos, reforça o "lugar da vítima" e dificulta o enfrentamento da violência.

Quando os dominados aplicam àquilo que os domina esquemas que são produto da dominação ou, em outros termos, quando seus pensamentos e suas percepções estão estruturados em conformidade com as estruturas mesmas da relação de dominação que lhes é imposta, seus atos de conhecimento são, inevitavelmente, atos de reconhecimento da submissão.

A idéia associada à relação sexual forçada, ao contrário das idéias associadas a sofrimento e distúrbio do comportamento, que são mais recorrentes nas falas dos profissionais dos dois grupos de maternidades, está mais presente, contraditoriamente, nos depoimentos daqueles que atuam na maternidade que não é considerada de referência. Isso, se por um lado, aponta para a necessidade de um maior investimento nas capacitações dos profissionais das unidades de referências, por outro, indica que os profissionais da unidade que não é considerada de referência vêm construindo uma representação na perspectiva da garantia de direitos.

Analisando as idéias que representam a violência sexual, observa-se que, mesmo nas maternidades de referência, onde os profissionais de saúde tiveram capacitações dirigidas à prevenção da violência sexual, ainda há muitos elementos de pré-conceito ou de reducionismo próprios do senso comum. São exemplos 
disso, o privilegiamento da patologização do problema e a ênfase no lugar da mulher como vítima, em detrimento da representação da mulher enquanto sujeito de direitos. Nesse sentido, nos dois grupos de maternidade estudados, verifica-se uma ambigüidade de idéias dos profissionais para representar a violência sexual cometida contra a mulher, que ora lançam mão de aspectos técnicos, sobretudo da área biomédica, ora se utilizam idéias do senso comum.

\section{As explicações da violência sexual cometida contra a mulher}

Uma outra forma de se ter acesso às representações sociais da violência sexual cometida contra as mulheres é por meio das explicações que as pessoas elaboram para justificar a ocorrência de tal problema. As "explicações da violência sexual”, comuns e contraditórias, presentes nos discursos dos profissionais de saúde referem-se aos seguintes núcleos de sentido: (1) relações de gênero, (2) violência urbana e (3) imputação de culpa à mulher. Tais explicações reproduzem noções tradicionalmente androcêntricas e, ao mesmo tempo, apresentam potencial revelador e transformador de relações assimétricas 9 .

O núcleo de sentido que se refere às relações de gênero reflete a explicação de que as interações sexuais intraconjugais são, ao mesmo tempo, conseqüência e manifestação de um direito reivindicado pelos sujeitos e ocupam um lugar no feixe de manifestações de afeição, de apego e de reciprocidade. Os profissionais entrevistados explicam que a violência sexual ocorre "muitas vezes [quando] ela [esposa] não está com vontade de ter ato sexual e o marido acha que ela tem obrigação" (N3). Gomes 26 destaca que o entendimento da violência contra a mulher, como reflexo das relações de gênero, aparece como tendência da produção bibliográfica de toda a década de 90, na área da saúde.

Essa representação, por vezes, é crítica em relação à submissão da mulher aos desejos sexuais masculinos, pois fere "a noção (...) de igualdade em qualquer campo entre todos os seres [e observa que] a mulher [muitas vezes] não quer ou não sabe como sair dessa história e tem medo de sair, até por conta dessa dominação que o homem exerce, do comer, dos filhos, do morar, ela não se sente forte o suficiente" (Ma4). Traz reflexos de uma cultura androcêntrica, traduzida pela "cultura de o homem ser o comedor, é também a cultura da mulher ser submissa [e] dependente (...) financeiramente do marido" (Ma6).
Por outro lado, as explicações parecem endossar uma idéia do imaginário social de que o casamento envolve a assinatura de um documento que implica no "consenso de [a mulher] ter relação sexual [e se entregar] inteiramente para o homem [por ter assinado tal documento]" (Ma9).

As profissionais do sexo feminino, ao explicarem a violência sexual fundamentando-se na perspectiva de gênero, em diferentes ocasiões, se reconheciam como integrantes do mesmo contexto que as mulheres em geral e algumas relataram experiências violentas.

Portella 27, ao abordar as crenças que legitimam a violência, as associa aos costumes e modos de homens e mulheres se comportarem dentro do casamento e em sociedade, e às formas de controle mútuas, como parte do amor e da hierarquia existente no casal. Nessas relações, o homem tem o poder de definir as regras da convivência conjugal. Referindo-se à violência sexual, afirma que "(...) se baseia na idéia de que é o desejo masculino que orienta o ato sexual, autorizando, portanto, o uso de violência quando a mulher, por qualquer razão, não cede a este desejo" 27 (p. 18). De acordo com Minayo 28 , a violência contra a mulher está vinculada à distribuição desigual do poder e às relações assimétricas que se estabelecem entre homens e mulheres, perpetuando a desvalorização do feminino e sua subordinação ao masculino.

Tal assimetria pode ser expressa no caso dos homens que buscam relações sexuais como uma forma de conquista sexual. Na busca dessa conquista podem recorrer "à violência (...), ainda que o uso de violência contra mulheres e a crença em 'conquistas sexuais' sejam também provenientes de visões tradicionais sobre masculinidades" 29 (p. 15).

A suposta superioridade masculina impõe uma série de normas sexistas que se desenvolvem de diferentes formas como a relação sexual indesejada e a responsabilidade pelo controle da fecundidade. Supõe-se que os homens sabem mais sobre sexo e que para iniciá-lo têm um impulso mais intenso e ativo; em contrapartida, as mulheres são mais passivas e receptivas. Essa classificação rígida e limitada considera que supostamente os homens querem sexo, em virtude de um impulso sexual inato e irreprimível, enquanto as mulheres buscam o amor 30 .

O segundo núcleo de sentido que articula as idéias explicativas acerca da ocorrência da violência sexual contra a mulher se ancora numa representação mais ampla de violência. Trata-se da sua articulação com a violência urbana, cujas idéias associadas são agressão, crime e problema social. A idéia da violência sexual como parte da violência urbana reforça a 
noção do senso comum de que a violência sexual contra a mulher, tipificada criminalmente, é cometida por estranhos e ocorre em via pública, como uma decorrência da violência em geral ocorrida na sociedade. Ou, em outras palavras, a violência sexual seria uma decorrência do clima violento que impera no espaço urbano. Nesse sentido, a violência sexual cometida por estranhos é vista como uma agressão ou crime, diferentemente do que ocorre quando perpetrada por parceiro íntimo.

Ainda nesse núcleo de sentido, os profissionais entrevistados associam a ocorrência da violência sexual, a problemas sociais como, por exemplo, fatores sócio-econômicos, pobreza e desemprego. A violência, então, ocorreria em "em todas as classes sociais (...) devido inclusive à situação sócio-econômica das pessoas, problema de emprego" (Oa3).

No âmbito da tipificação criminal da violência sexual, o estupro assume destaque tanto pela sua incidência quanto pelo seu efeito simbólico. As notificações de estupro cresceram 65\% no período de 1991 a 1999, nas Delegacias Distritais e nas Delegacias Especiais de Atendimento a Mulher do Rio de Janeiro. Esse aumento pode estar indicando mudanças positivas no comportamento das mulheres e da sociedade no que diz respeito aos direitos da mulher 31.

Vigarello 24 , ao analisar a trajetória histórica do estupro, desde a configuração de crime moral até o seu reconhecimento na esfera do direito, aponta que a visão do prazer apaga a agressividade, impondo o desejo como uma evidência à qual a vítima é, confusamente, associada e exposta ao olhar público.

Neste eixo, ocorre um deslocamento da violência sexual do espaço privado para o espaço público, num contexto urbano de desigualdade social 32 , que confere uma maior legitimidade às vítimas, dado que a violação aparece como inevitável.

Por último, existe um terceiro núcleo de sentido nas falas dos profissionais entrevistados para explicar a violência sexual: a imputação da culpa à mulher. Na representação desses profissionais, a mulher é violentada "porque quando ela não se dá ao respeito, ela favorece que ela seja desrespeitada" (Ma13). Referem que sua forma de vestir pode favorecer o crime e a agressão: "elas estão de microssaia (...) não é minissaia não (...).. muitas com os seios praticamente todos à mostra" (Eol).

Tal explicação traz, explicita e implicitamente, a idéia de que os comportamentos femininos são promíscuos e classificados com termos não abonadores como não respeitoso, incorreto, desprotegido, desviante e liberado. Tal classificação inclui julgamento sobre a roupa, o local freqüentado, os horários em que a mulher transita nas ruas e as companhias com quem se relaciona.

Em diferentes falas, a idéia da violência sexual é então associada a castigo pela liberdade assumida pelas mulheres na sociedade. Tais representações são parte da cultura sexista e preconceituosa, discriminando o desejo feminino de liberdade: "querem liberdade demais muito cedo, [elas] foram ao encontro mesmo dessa violência" (Ea4).

Numa leitura androcêntrica, a autonomia conquistada pelas mulheres acaba por gerar comportamentos estranhos. Dentro dessa visão, o castigo aparece como alternativa de controle da sexualidade, recolocando a mulher no seu espaço de origem, ou seja, o âmbito privado, ao qual deveria se resignar e nele se circunscrever. A família, nesse contexto repressivo, é vista como a instituição responsável por controlar a liberdade sexual e a emancipação feminina, vistas como causas da violência sexual.

Esse núcleo de sentido evidencia a associação do ser feminino com as idéias de sedução, de pecado e de responsabilidade em relação à atração sexual do homem. Ou seja, por uma lógica contraditória, a mulher sempre pode ser considerada culpada pelos ataques sexuais de que é vítima. Tais entendimentos são reflexos da representação de que a mulher tem uma posição subordinada e secundária em relação aos desejos masculinos, não lhe cabendo ser ativa. Por outro lado, de forma ambígua, algumas falas culpam a mulher por não denunciar a violência masculina, denotando sua "acomodação (...) falta de iniciativa e conivência" (Ea3).

As explicações da violência sexual atribuídas às relações de gênero estão presentes nos discursos dos profissionais de saúde das maternidades consideradas de referência, o que pode ser resultante de certa incorporação das noções trabalhadas nas capacitações. As explicações relacionadas à violência urbana e à imputação à mulher são mais notadas nos discursos da maternidade que não é considerada de referência.

\section{Considerações finais}

Em relação às representações sociais da violência sexual contra a mulher presentes nos discursos dos profissionais de saúde da assistência pré-natal, a pesquisa mostrou que a reprodução cultural de estereótipos vem solidificando percepções sexistas e reducionistas contra as mulheres. Isso configura, apesar de todos os avanços conseguidos pelo feminismo, a persistência dos padrões hegemônicos de relações 
assimétricas que servem para explicar e fornecer elementos de conservadorismo.

As representações sociais dos profissionais das maternidades que são referência para o atendimento às vítimas de violência sexual, mesmo após o processo de capacitação e a experiência acumulada no atendimento, continuam a ser informadas por tal padrão hegemônico, que legitima e naturaliza a violência sexual, apesar da análise comparativa permitir afirmar alguns pontos de diferenciação entre os dois grupos de maternidades.

As idéias associadas à violência sexual apontam para a ambigüidade nos discursos dos profissionais entrevistados, que ora utilizam uma leitura biomédica sobre o assunto, ora se reduzem ao senso comum. As explicações da violência sexual, por um lado, são relacionadas com a desigualdade de gênero, mas, por outro, ainda reproduzem preconceitos não superados na nossa cultura.

É importante, portanto, aprofundar essa discussão na capacitação dos profissionais que atuam na prevenção da violência sexual, buscando fundamentar este esforço no fato de que as representações, que expressam a espessura da cultura, podem ser modificadas e não apenas reproduzidas.

A perspectiva de gênero e o respeito à especificidade de cada um deles constituem elementos básicos de uma nova estruturação social e de direitos que contemplem a humanida-

\section{Resumo}

Pretende-se analisar as representações sociais da violência sexual contra a mulher, construídas e reproduzidas no contexto da assistência pré-natal em três maternidades públicas municipais do Rio de Janeiro, Brasil. Essa pesquisa, de abordagem qualitativa, trabalhou com dois núcleos temáticos: as idéias e as explicações da violência sexual cometida contra a mulher. As 45 entrevistas realizadas com os profissionais de saúde foram trabalhadas mediante análise de conteúdo temático. Os resultados apontam que as representações sociais sobre a violência sexual cometida contra a mulher se encontram associadas às idéias de sofrimento, distúrbio do comportamento e relação sexual forçada. As explicações para a ocorrência desse tipo de violência referem-se às relações de gênero, à violência urbana e à imputação de culpa à mulher. Pode-se concluir que persistem padrões hegemônicos de relações assimétricas, mesmo nos discursos profissionais das maternidades que são referência para o atendimento às vítimas de violência sexual. A incorporação da categoria analítica de gênero, por intermédio das capacitações e da formação profissional, poderia tornar a assistência pré-natal numa importante "porta de entrada" para se abordar as situações de violência sexual.

Violência; Saúde da Mulher; Cuidado Pré-Natal de como um todo. Logo, a adoção, pelos profissionais, da categoria analítica relacional de gênero poderia permitir-lhes uma compreensão mais crítica da violência sexual contra a mulher, vinculando-a à distribuição desigual do poder e às relações assimétricas que se estabelecem entre homens e mulheres na sociedade, perpetuando a desvalorização do feminino e sua subordinação ao masculino.

Um posicionamento dirigido à prevenção da violência sexual implica num deslocamento da representação da sexualidade feminina - de caráter essencialista e informada por um paradigma biomédico - para uma representação centrada na autonomia feminina e no reconhecimento dos direitos sexuais e reprodutivos.

Em virtude da magnitude e da complexidade da violência sexual cometida contra a mulher, sua prevenção requer ações eficientes e capazes de impactar favoravelmente a realidade vivida pela população feminina. Neste sentido, a assistência pré-natal pode tornar-se uma importante "porta de entrada" para se abordar as situações de violência sexual, devendo favorecer o acolhimento, incorporar dados sociais, encorajar a notificação e estabelecer vínculos, de modo a servir de referência para a mulher atendida. Todavia, isso pressupõe uma intervenção profissional capaz de recriar representações sociais ancoradas na autonomia feminina e na garantia de direitos.

\section{Colaboradores}

L. F. Cavalcanti participou no planejamento da pesquisa, na coleta e análise dos dados. R. Gomes e M. C. S. Minayo contribuíram no planejamento da pesquisa e na análise dos dados. O trabalho de revisão e redação do artigo foi desenvolvido de forma conjunta, com um freqüente debate entre os autores, considerando o conhecimento acumulado por cada um. 


\section{Referências}

1. Cavalcanti LF. Ações da assistência pré-natal voltadas para a prevenção da violência sexual: representação e práticas dos profissionais de saúde [Tese de Doutorado]. Rio de Janeiro: Instituto Fernandes Figueira, Fundação Oswaldo Cruz; 2004.

2. Campos JR, Nascimento LG, Almeida Jr WJ, Vaintraub MT, Silva HMS, Lopes GP. Violência sexual em Belo Horizonte: pesquisa no Instituto Médico-Legal. J Bras Ginecol 1994; 104:227-30.

3. Frye V. Examining homicides's contribution to pregnancy-associated deaths. JAMA 2001; 285:1 510-1.

4. Sable MR, Fieberg JR, Martin SL, Kupper LL. Violence victimization experiences of pregnant prisoners. Am J Orthopsychiatry 1999; 69:392-7.

5. World Health Organization. World report on violence and health. Geneva: World Health Organization; 2002.

6. Drezett J. Contracepção de emergência e violência sexual. http://www.ipas.org.br/arquivos/jefferson/CLAE.doc (acessado em 01/Dez/2003).

7. Jewkes R, Vundule C, Maforah F, Jordaan E. Relationship dynamics and teenage pregnancy in South Africa. Soc Sci Med 2001; 52:733-44.

8. Trajano AJB, Gomes R, Silva LGP, Trajano TCG, Mendes CHF. Gravidez e sexualidade: medo e desejo. Estudo qualitativo com puérperas em duas maternidades públicas do Rio de Janeiro. J Bras Ginecol 1998; 108:395-403.

9. Minayo MCS. O desafio do conhecimento: pesquisa qualitativa em saúde. São Paulo: Editora Hucitec/Rio de Janeiro: ABRASCO; 1994.

10. Gomes R. O corpo na rua e o corpo da rua. A prostituição infantil feminina em questão. São Paulo: Unimarco Editora; 1996.

11. Herzlich C. A problemática da representação social e sua utilidade no campo da doença. Physis (Rio J.) 1991; 1:23-36.

12. Gomes R, Mendonça EA. A representação e a experiência da doença: princípios para a pesquisa qualitativa em saúde. In: Minayo MCS, Deslandes SF, organizadores. Caminhos do pensamento: epistemologia e método. Rio de Janeiro: Editora Fiocruz; 2002. p. 109-32.

13. Bardin L. Análise de conteúdo. Lisboa: Edições $70 ; 1977$.

14. Gomes R. A análise de dados em pesquisa qualitativa. In: Minayo MCS, organizador. Pesquisa social: teoria, método e criatividade. Petrópolis: Vozes; 1994. p. 67-80.

15. Buvinic M, Morrison AR, Shifter M. Violência nas Américas: um plano de ação. In: Morrison AR, Biehl ML, organizadores. A família ameaçada: violência doméstica nas Américas. Rio de Janeiro: Editora FGV; 2000. p. 19-48.

16. Giffin K. Violência de gênero, sexualidade e saúde. Cad Saúde Pública 1994; 10 Suppl 1:146-55.
17. Helman CG. Gênero e reprodução. In: Helman CG, organizador. Cultura, saúde e doença. Porto Alegre: Artes Médicas; 1994. p. 137-64.

18. Schraiber LB, D’Oliveira AFLP. Violência contra mulheres: interfaces com a saúde. Interface Comun Saúde Educ 1999; 3:11-26.

19. Rozemberg B, Minayo MCS. A experiência complexa e os olhares reducionistas. Ciênc Saúde Coletiva 2001; 6:115-23.

20. Machado LZ. Masculinidade, sexualidade e estupro. Cad Pagu 1998; 11:231-73.

21. Bourdieu P. A dominação masculina. Rio de Janeiro: Bertrand Brasil; 1999.

22. Rede Nacional Feminista de Saúde e Direitos Reprodutivos. Saúde da mulher e direitos reprodutivos: dossiês. São Paulo: Rede Nacional Feminista de Saúde e Direitos Reprodutivos; 2001.

23. Zegarra-Tarqui M. Redes locales frente a la violencia familiar. Lima: Organización Panamericana de la Salud, Organización Mundial de la Salud; 1999. (Serie Violencia Intrafamiliar y Salud Pública. Documento de análisis n. 2).

24. Vigarello G. História do estupro: violência sexual nos séculos XVI-XX. Rio de Janeiro: Jorge Zahar Editor; 1998.

25. Bourdieu P. O poder simbólico. Rio de Janeiro: Bertrand Russel; 1989.

26. Gomes R. A mulher em situações de violência sob a ótica da saúde. In: Minayo MCS, Souza ER, organizadores. Violência sob o olhar da saúde: a infrapolítica da contemporaneidade brasileira. Rio de Janeiro: Editora Fiocruz; 2003. p. 199-222.

27. Portella AP. Abordagem social sobre violência e saúde das mulheres. Jornal da Rede Feminista de Saúde 2000; 22:17-9.

28. Minayo MCS. Violência contra a mulher, problema de saúde pública. Palavra da Ciência. http:// www.fiocruz.br/ccs/mulher.htm (acessado em 05/ Abr/1999).

29. Acosta F. Homens, violência de gênero e saúde sexual e reprodutiva: um estudo sobre homens no Rio de Janeiro/Brasil. Rio de Janeiro: Instituto NOOS de Pesquisas Sistêmicas e Desenvolvimento de Redes Sociais; 2003.

30. Giddens A. A transformação da intimidade: sexualidade, amor e erotismo nas sociedades modernas. São Paulo: Editora UNESP; 1993.

31. Instituto Superior de Estudos Religiosos. Indicadores de violência e acidentes no Rio de Janeiro. http://www.iser.org.br (acessado em 30/Dez/ 2003).

32. Chesnais JC. A violência no Brasil. Causas e recomendações políticas para a sua prevenção. Ciênc Saúde Coletiva 1999; 4:53-68.

Recebido em 09/Set/2004

Versão final reapresentada em 05/Jul/2005

Aprovado em 13/Jul/2005 